\title{
TMJ involvement in ankylosing spondylitis
}

\author{
Sandeep Chaurasia', Navdeep Johar,", Gauri Barkale ${ }^{3}$, Trishna Rahangdau ${ }^{4}$, Tushar Phulambrikar ${ }^{5}$ \\ ${ }^{1}$ PG Student, ${ }^{2}$ Lecturer, ${ }^{3}$ PG Student, ${ }^{4}$ PG Student, ${ }^{5}$ Professor, Dept. of Oral Medicine \& Radiology, Sri Aurobindo College of \\ Dentistry, Indore, Madhya Pradesh, India
}

*Corresponding Author: Navdeep Johar

Email: docnav1999@gmail.com

\begin{abstract}
Ankylosing spondylitis (AS) is a chronic auto-inflammatory disease of the joints, belonging to the group of spondyloarthropathic disorders. The disease has a crippling effect on the axial skeleton and its progression to the later stages can have a debilitating effect on the patient. It has an under-diagnosed pathology and enigmatic pathophysiology. A strong genetic link has been found with the help of genome screening. Frequency of temporomandibular joint (TMJ) involvement in patients with ankylosing spondylitis (AS) has varied from $4 \%$ to $35 \%$. It is more common in men and produces generalised stiffness in involved joints. Clinician should be suspicious of AS when a patient reports with painful restricted movements of joint, neck or back and with no trauma history. Conventional radiographic methods have allowed the demonstration of TMJ abnormalities in patients with AS, but cone beam computed tomography (CBCT) is necessary to establish joint space relations and bony morphology. We describe a case of severe AS with TMJ involvement in a 34-year-old male patient and demonstrated TMJ changes on CBCT.
\end{abstract}

Keywords: Ankylosing spondylitis, Spondylo-arthropathic disorders, Temporomandibular joint, Cone beam computed tomography.

\section{Introduction}

Ankylosing spondylitis (AS) also known as Bechterew's disease or Marie Strumpell disease is a chronic autoimmune inflammatory disorder of the joints, associated to spondyloarthropathic disorders. ${ }^{1,2}$ On the basis of previous studies conducted, the male/female ratio is in favor of men ranging between 2.4:1 and 18:1. ${ }^{3}$ The disease affects synovial and cartilaginous articulations and the sites of tendon and ligament attachment to bone. The current diagnostic criteria include axial symptoms, limitation of spinal movements and radiological evidence of sacroilitis. ${ }^{4}$ Immunological activity is suggested by the presence of human leukocyte antigen (HLA- B27) in over $90 \%$ of patients with AS.

Arthritis of the TMJ with AS is less well recognized. The most common clinical symptoms are pain and tenderness in the TMJ region with limited jaw opening. The supposition that there is an arthritic involvement of the TMJ in patients with ankylosing spondylitis is by the radiological findings such as erosions or massive deformity of the condyle in combination with pain and/or restricted mouth opening. ${ }^{3}$ Panoramic radiography can be used to compare both the joints directly. CBCT scanning represents the best imaging modality for the detection of osseous anatomy and pathology. ${ }^{3}$

Non-steroidal anti-inflammatory drugs (NSAIDs) are the first line of drugs and they effectively relieve symptoms. NSAIDs refractory patients are treated with second line drugs for e.g. corticosteroid, diseasemodifying anti-rheumatic drugs (DMARDs), pamidronate, etc. ${ }^{5}$

\section{Case Presentation}

A 34-year old man reported to the department with a history of limited mouth opening and pain in left mandibular posterior tooth region since 20 days. He also gave the history of morning stiffness of jaws and watering of eyes. The patient had a medical history of AS diagnosed by an orthopaedician since 8 years.

There was involvement of all the facet joints of spine resulting in thoracolumbar kyphosis. He was unable to look up and the symptoms gradually worsened. He had no history of trauma or any pathology of the TMJ. The patient also reported a habit of chewing dried areca nut powder 5-6 times per day for the past 3 years. He occasionally mixed calcium oxide with areca nut powder. Examination revealed that mouth opening was limited to about $21 \mathrm{~mm}$ (Fig. 1). His oral cavity was fully blanched and thick fibrotic bands were palpable bilaterally on the buccal mucosa. There was also marked neck flexion and forward thrusting of head (Fig. 2). Condylar movement was also restricted.

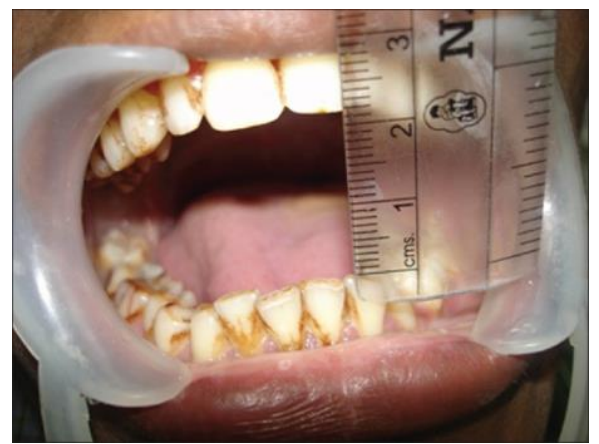

Fig. 1: Restricted mouth opening with inter-incisal distance $21 \mathrm{~mm}$ 


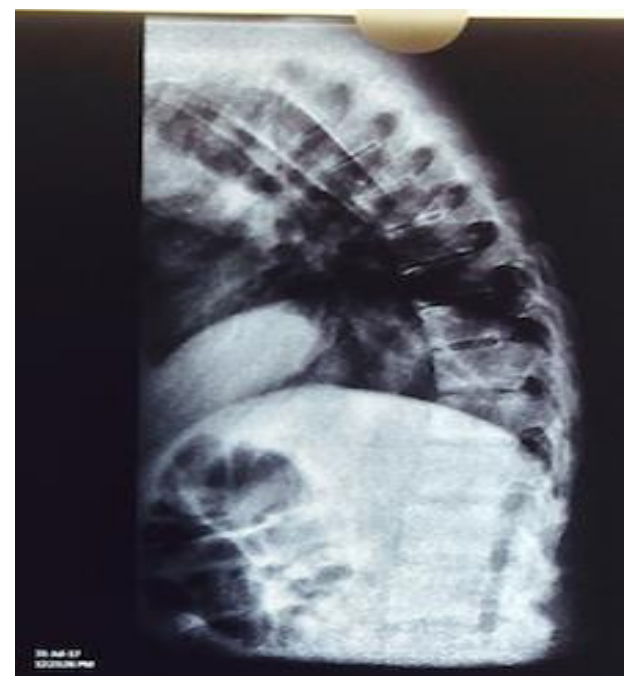

Fig. 2: Radiograph shows neck flexion and forward thrusting of head

\section{Investigations}

The relevant laboratory findings were decreased haemoglobin that is $7.2 \mathrm{gm} \%$, positive HLA-B27 and negative rheumatoid factor. MRI scan of the lumbar spine was performed using $\mathrm{T} 1$ and $\mathrm{T} 2$ weighed sequences in multiple planes. MRI findings revealed straightening of lumbar spine curvature leading to classic "Bamboo spine" appearance (Fig. 3). Multilevel disc degeneration were seen in the form of dessication. Spinal canal and neural foramina were found to be adequate in size. Pelvic radiography showed bony erosions along with sclerosis in ischeal tuberosity and iliac crest (Fig. 4).

Panoramic radiography and CT demonstrated TMJ changes with condylar erosions on both sides and narrowed joint space (Fig. 5 and 6).

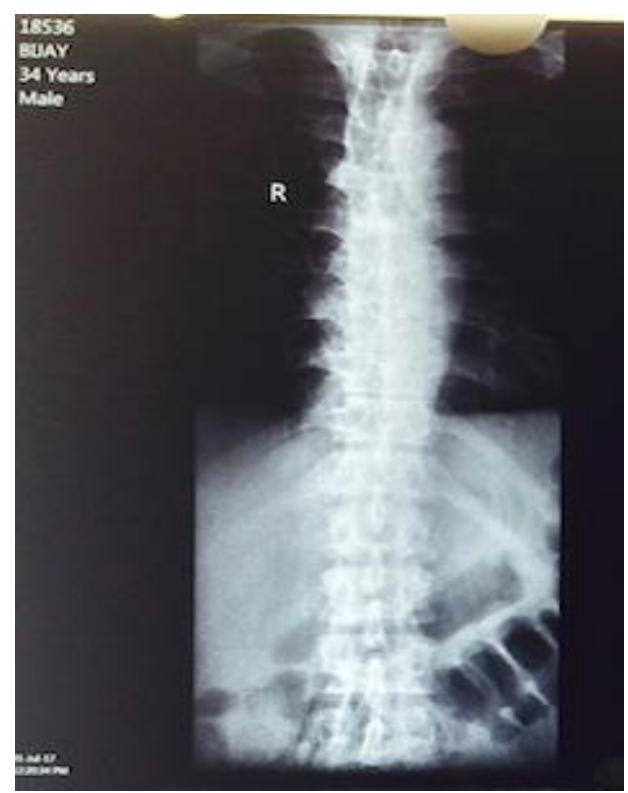

Fig. 3: Lumbar spine radiograph shows classic "Bamboo spine" appearance

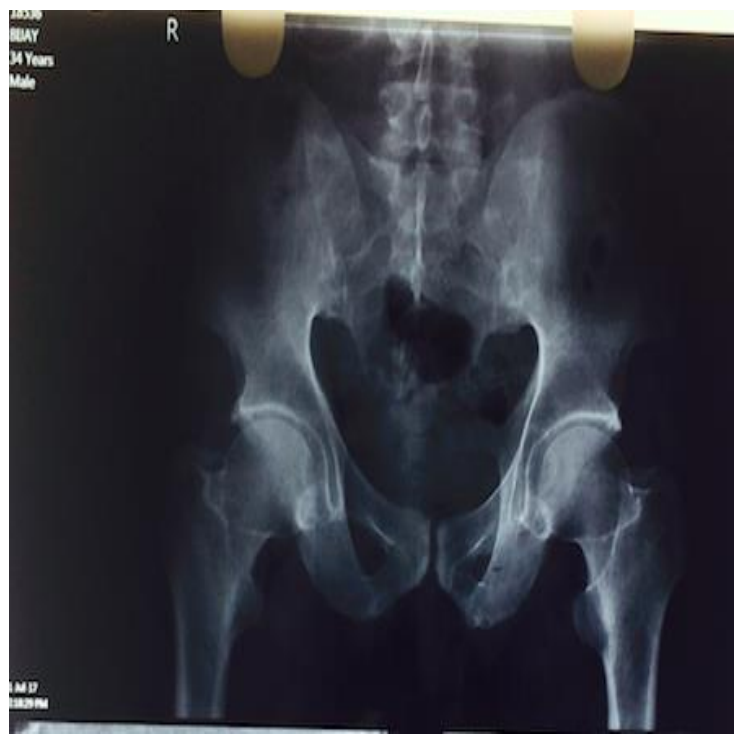

Fig. 4: Conventional radiograph of the pelvis shows bony erosions along with sclerosis in ischeal tuberosity and iliac crest

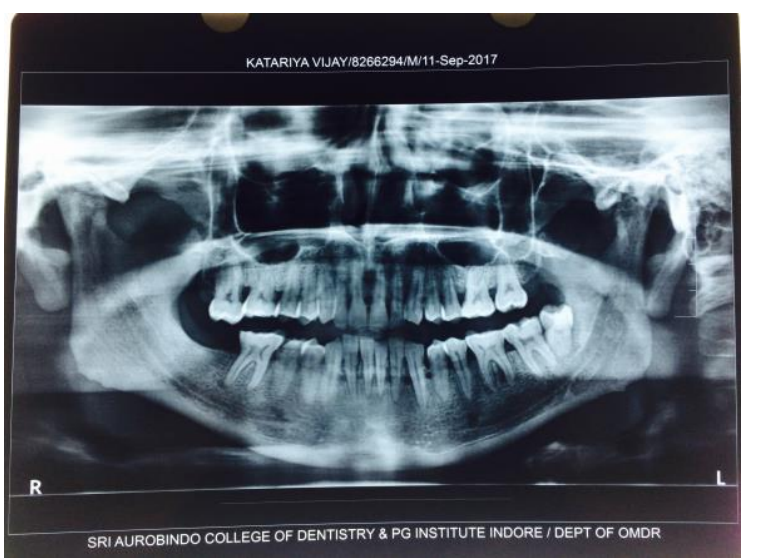

Fig. 5: Panoramic radiograph showing bilateral erosion of condyle and narrowing of joint space

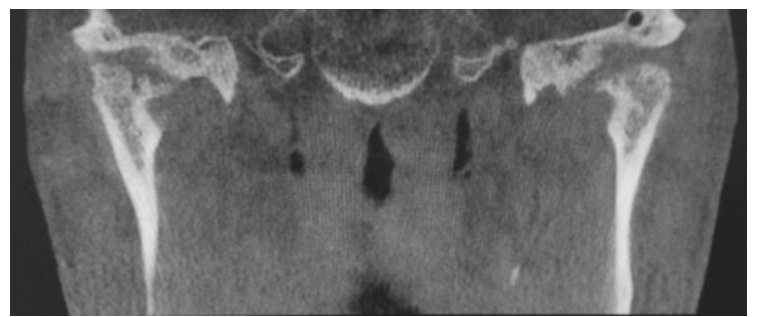

Fig. 6: CBCT (coronal view) of temporomandibular joint (TMJ). Both right and left side show erosive changes and narrowed joint space, seen more prominently on right side

\section{Discussion}

The involvement of TMJ in AS suggest extensive spinal disease and peripheral joint involvement than the remaining patients. It gives rise to few serious symptoms until gross restriction of jaw movement has occurred, this is in contrast to the symptoms occurring 
in rheumatoid arthritis, which usually resolves spontaneously and rarely gives rise to permanent restriction of jaw opening. ${ }^{1}$

The flexion deformity of the neck and rigidity of the cervical spine in the patient caused difficulty in assessing TMJ function due to approximation of chin to the chest. ${ }^{6}$ Davidson et al. ${ }^{6}$ reported that the restricted mouth opening in the patients with AS could be due to proximity of chin to the neck. Wenghoefer et al. ${ }^{7}$ found that the limitation of jaw mobility in those patients might also be caused by an elongation of the mandibular coronoid process. In the present case, there is approximation of chin to chest due to involvement of cervical spine. Approximately half of the affected patients had unilateral involvement of TMJ. ${ }^{8}$ In the present case there was a bilateral involvement of TMJ.

Helenius et al. ${ }^{9}$ reported that patients experienced pain, stiffness, headache and restricted movements in TMJ. It has been suggested that compression of retrodiscal tissue may be the cause of such pain. Wenneberg and Kopp (1982) ${ }^{10}$ reported that in the patient group, $13 \%$ has restricted mouth opening and $31 \%$ was tender to palpation of the TMJs compared with control group, with $4 \%$ having restricted mouth opening and $1 \%$ having pre-auricular tenderness. Similarly, our patient presented with restricted mouth opening, morning stiffness of jaws, headache, no clicking sounds and restricted condylar movements. He also complained of ocular symptoms, which included frequent watering of eyes.

Ramos-Remus et al. ${ }^{8}$ found that AS had more variability in TMJ mobility than controls and showed increased frequency of condylar erosions, flattening, sclerosis and temporal flattening. Resnick (1974) ${ }^{11}$ reported that $32 \%$ of his sample of 25 consecutive patients with AS had tomographic TMJ abnormalities. The most common feature was joint space narrowing, followed by erosions, reduced mobility, osteophyte formation, excessive sclerosis and extensive erosion. ${ }^{8}$

In the present case, panoramic radiography and CBCT revealed condylar erosion and abnormal shape of condyle bilaterally. A better radiographic method for the condyle, the joint space and the articular fossa is CBCT. ${ }^{3}$ Condylar erosions were reported to be correlated with the severity and duration of AS and are diagnostic of degenerative change in osseous tissue. ${ }^{8}$

The mechanism by which TMJ involvement is seen in patients with AS is unclear; however, there are two potential mechanisms for the pathogenesis of TMJ involvement in AS. One could involve the destruction of the capsular or disc attachment, resulting in internal derangement and subsequent degenerative joint diseases. Alternatively, there could be a primary synovitis with direct breakdown of the articular surfaces. Internal derangement would then result from articular surface changes and not precede them. Hypermobility was the most common finding. ${ }^{1}$

Cervical dysfunction, with neck complaints as a presenting symptom, and atlanto-axial subluxation were significantly associated with advanced TMJ involvement as evident by erosions. AS causes debilitating postural changes with forward thrusting of the head. ${ }^{8}$

Treatment is multidisciplinary and may involve many specialists from the outset. Physiotherapy, preferably with a specific AS exercise program, is essential in helping to maintain posture and prevent fusion of the spine. Anti-inflammatory medications are still a major part of symptomatic treatment. DMARDs such as sulfasalazine, methotrexate, hydroxychloroquine sulfate, etc can be effective in peripheral joint inflammation. Anti-TNF- $\alpha$ therapies are the most exciting treatment modalities till date. Infliximab and etanercept are now licensed for the treatment of AS. ${ }^{5}$

\section{References}

1. Arora P. Temporomandibular joint involvement in ankylosing spondylitis. BMJ. Case report. 2013;1-4.

2. Kumar S. A Review on Ankylosing Spondylitis. Ijpbs. 2011:2(3);186-193.

3. Locher MC, Felder M, Sailer HF. Involvement of the temporomandibular joints in ankylosing spondylitis (Bechterew's disease). J Craniofac Surg. 1996:24;20513.

4. Deesomchok Q, Tumrasvin T. Clinical study of Thai patients with ankylosing spondylitis. J Clin Rheumatol. 1985;4;76-82.

5. Ghosh A, Kole A, Devi GI. Treatment of ankylosing spondylitis with special reference to biologics: single centre experience. J Indian Rheumatol Assoc. 2004;12;54-7.

6. Davidson C, Wojtulewski JA, Bacon PA. Temporomandibular joint disease in ankylosing spondylitis. Ann Rheum Dis. 1975;34;87-91.

7. Wenghoefer M, Martini M, Allam JP. Hyperplasia of the coronoid process in patients with ankylosing spondylitis (Bechterew disease). J Craniofac Surg. 2008;4;1114-18.

8. Ramos-Remus C, Major P, Gomej-Vargas A. Temporomandibular joint osseous morphology in a consecutive sample of ankylosing spondylitis patients. Ann Rheum Dis. 1997;56;103-7.

9. Helenius LMJ, Hallikainen D, Helenius I. Clinical and radiographic findings of the temporomandibular joint in patients with rheumatic diseases. A case control study. Oral Surg Oral Med Oral Pathol Oral Radiol Endod. 2005;99;455-63.

10. Wenneberg B, Kopp S. Subjective symptoms from the stomatognathic system in ankylosing spondylitis. Acta Odontol Scand. 1982;40:215.

11. Resnick D. Temporomandibular joint involvement in ankylosing spondylitis. Comparison with rheumatoid arthritis and psoriasis. Radiology. 1974;112:587-91. 